\title{
Computer Aided High Strength Concrete Mixture Proportion using Mat Lab
}

\author{
D.Zealakshmi \\ PhD Student, \\ Department of Civil \\ Engineering \\ Pondicherry University
}

\author{
A.Ravichandran \\ Principal, \\ Christ College of Engineering \\ \&Technology, Puducherry
}

\author{
S.Kothandaraman \\ Professor, \\ Department of Civil \\ Engineering \\ Pondicherry Engineering \\ College, Puducherry.
}

\begin{abstract}
This paper presents a computer aided mix design for high strength concrete is based on the guideline given in ACI 211.4R-93.Design of concrete mix is extremely complicated since it involves many process and more efforts is required to understand the data given in tables and interpolations also needed frequently when intermediate values are required. Hence the manual process of calculating the mix design may also leads to the human error as the data may be mistakenly handled by the person. The program has been developed and the values have been cross checked with the manual calculation and also have been verified with the various research reports such as mix proportion utilized in (ACI 2114R-93)(CPA 1995) and also compared with the other mix proportion whose compressive strength is $60 \mathrm{Mpa}$ at 28 days.
\end{abstract}

Hence the main objective of this paper is to develop a computer aided program to produce the accurate and reliable results within the short period of time and to predict the optimum mix proportion for high strength concrete incorporating silica fume as a partial replacement of cement.

Keywords: Computer aided Mix design, Mat lab, and High strength concrete.

\section{INTRODUCTION}

Now a day's high strength concrete and high performance concrete are being widely used all over the world. Most applications of high strength concrete have been used in high rise buildings, long Span bridges and some special applications in structures. In developed countries, using High strength concrete in structures today would result in both technical and economic Advantage. ${ }^{[1]}$

Development of mix design method plays a key not in concrete technology. It involves the process of determining experimentally the most suitable concrete mixes in order to achieve maximum strength with at least economic expenditures. ${ }^{[2]}$

Design of concrete mixes involves determination of the proportions of the given constituents namely, cement, water, coarse aggregate and fine aggregate with admixtures. Workability is specified as the important property of concrete in the fresh state and compressive strength and durability will be considered for the hardened state.

The mix design methods being followed in different countries are mostly based on empirical relationships, charts and graphs developed from extensive experimental investigations. Even though we have several methods are in practice, the method proposed by the American Concrete Institute has been utilized in this work ${ }^{[5]}$. Since ACI Mix design method is an originator for all other methods, including Indian standard method, wherein every table and charts are fully borrowed from ACI.

Based on the experience gathered from the various literatures and also with the reference to (ACI 211 - 4R-93) mix design of HSC has been calculated however the use of this method is a tedious task and since the process is lengthy and it has to refer more number of tables and charts. And, the values must be interpolated based on the data required.

The manual process of calculating the mix design leads to the human error because of improper handling of data and also a time consuming process hence, computer aided mix design of high strength concrete has been developed .

Most of the researcher has used spread sheets for mix design which means that Computation of the ingredients used in concrete using formula without using tables. Apart from all the methods used so far this program has been developed will produce the accurate and reliable results within the short period of time and the values have been cross checked with the manual calculation. Therefore the development of Mat lab coding for HSC is worthwhile.

\section{SIGNIFICANCE OF THE RESERCH}

In recent times however, that the trend is towards the use of the computer for most computations, a computer-aided approach to the design of concrete mixes is becoming a welcome practice. ${ }^{[6]}$

Most of the research publications are available for concrete mix design with different techniques like Regression analysis, Neural network, Fuzzy logic etc. with different types of concrete such as HSC, HPC\& light weight concrete, but limited papers have been published especially on HSC, an example of such effort is the computerized mix design ${ }^{[6]}$ Hence the significance of this research work is to present a paper called computer aided mix design using ACI method for HSC whose compressive strength is M60 which is more simple and reliable.

\section{METHODOLOGY}

Now-a-days an attempt has been made towards the computer aided mix design. Computational approach and experimental analysis was done with the help of Mat lab.

Based on the method of mix design calculation arrived. The flow chart \&algorithm has been developed to show the nature of work as well as detailed outline of the program and also represent the inputs, calculation steps and the output. 


\subsection{DEVELOPMENT OF A PROGRAM}

The mat lab program has been proposed as an alternative solution for solving very tedious problems to find out the best mix proportions. Since there are several techniques are available in this concrete technology field comparatively this method is very simple to handle will produce the results such as mix design proportion for the different values.

These mat lab coding is developed by means of simple commands like if and else if .hence the tedious task has been handled flexibly by the given commands. And it does not require much knowledge for the workers about the computer as well about the concrete mix design because by changing the values of the required data itself as an input and after file saved the results will be displayed.

Finally the program has been tested with the different values for different trial mixes. The output received exactly match with the manual calculations. The program consists of three different stages are:

\section{Algorithm (coding) \& flowchart \\ 2. Restoring the program}

\subsection{INPUT\&OUTPUTDATA}

The following data's are required as an input such as:

1. Based on workability(slump value)

2. Maximum size of aggregate.

3. Concrete type (air-entrained concrete or non-air entrained concrete).

4. Mix design method (Weight method or volume method).

5. Compressive strength.

6. Fineness modulus of sand.

7. Oven dry lose weight of coarse aggregate.

8. Specific gravity factor.

9. Percentage of entrained air.

10. Total aggregate volume.

11. Volumes of fine and coarse aggregate.

12. Volumes of normal weight fine aggregate.

13. Dry unit weight of fine aggregate.

14. Dry unit weight of coarse aggregate.

The output produced from the mat lab program is:

1. Water content

2. Water cement ratio

3. Cement content

4. Weight of coarse aggregate

5. Weight of fine aggregate.

6. Water content.

7. Weight of cementious material

\subsection{DEVELOPMENT OF PROGRAM}

This method developed is to prepare the computer aided mix design for high strength concrete which involved with the algorithm and flow chart (Flow chart-1) is based on steps given ACI mix design method. Based on the method of mix design calculation arrived. The flow chart has been created to show the nature of work as well as detailed outline of the program, which represent the inputs, calculation steps and the output.

Case: 1(Volume method)The design mix of high strength concrete is required to have a compressive strength of $60 \mathrm{Mpa}$ and required slump starts at $50 \mathrm{~mm}$ , Max size of aggregate used $=12.5 \mathrm{~mm}$; Specific gravity of cement $=3.15$; Relative density of fine aggregate $(\mathrm{F} . \mathrm{A})=2.59$; Relative density of Coarse aggregate $(\mathrm{C} . \mathrm{A})=2.76$; Dry Rodded Bulk Density of fine aggregate $=105 \mathrm{lb} / \mathrm{ft} 3$; Dry Rodded Bulk Density of coarse aggregate $=101 \mathrm{lb} / \mathrm{ft} 3$; with the reference to the previous literature the values have been used and results produce will be converted to normal units

Case: 2(Weight method)Concrete mix has been designed for HSC to have a compressive strength of $60 \mathrm{Mpa}$ using the following data's such as Slump $=50 \mathrm{~mm}$; Maximum size of the aggregate: $12.5 \mathrm{~mm}$;Specific Gravity of Cement = 3.10 ; Specific Gravity of Fine Aggregate $=2.65$; Specific Gravity of Coarse Aggregate $=2.70$; Dry Density of Coarse Aggregate $=1560 \mathrm{~kg} / \mathrm{m} 3$; Water Cement Ratio = 0.403 ; Volume of dry rodded Coarse Aggregate $=0.64$ per unit volume of concrete; Fineness Modulus of Fine Aggregate $=$ 2.40; Fineness Modulus of Coarse Aggregate = 7.20.

Table- 1: Results of mix design (weight method)

\begin{tabular}{|c|c|c|}
\hline Ingredients & Base (manual) & Program results \\
\hline Cement(Kg) & 633 & 633 \\
\hline Silica fume(Kg) & - & \\
\hline CA(Kg) & 920 & 920 \\
\hline FA(Kg) & 710 & 710 \\
\hline Water(Kg) & 190 & 190 \\
\hline Air (\%) & $2 \%$ & \\
\hline
\end{tabular}

Table -2: Results of mix design (Volume method)

\begin{tabular}{|c|c|c|}
\hline INGREDIENTS & BASE(manual) & Program results \\
\hline Cement(Kg) & 435 & 435.10 \\
\hline Silica fume(Kg) & - & - \\
\hline CA(Kg) & 841.72 & 841.87 \\
\hline FA(Kg) & 676 & 675 \\
\hline Water(Kg) & 190 & 190 \\
\hline Air (\%) & $2 \%$ & $2 \%$ \\
\hline
\end{tabular}

From the table above it is evident that the values calculated using the mat lab coding matches with the manual calculations which means that this program is simple and efficient for mix design computation of high strength concrete for different trial batches 


\section{CONCLUSIONS}

The program has been developed in Mat lab using simple commands such as arithmetic operators, Relational operators \& conditional statements. The flow chart gives the detailed outline of the program which specifies the input and output for both absolute volume and weight basis method. An Output of the program have been represented in term of quantity of cement, fine aggregate, coarse aggregate, quantity of water required. And the program has been checked with the same type of problems from the source file. Hence the method of using computer aided techniques which avoids the error formed during calculations mainly in interpolating the data's. Therefore method is more flexible and is used to predict optimum mix proportion for HSC. Thus the program developed with the commands such as if \& else if, using mat lab software in a simple way and easily understandable manner and it also serve as a guidelines for beginners. This computer aided mix design developed will make use for high strength concrete to find out exact mix proportions in future without putting more effort.

\section{REFERENCES}

[1] Bhikshma, V., Nitturkar, K., and Venkatesham, Y., 2009, "Investigations on mechanical properties of high Strength silica fume concrete," Asian journal of civil engineering. (Building and housing), 10(3), pp.335-346.
[2] Yaqub,M., and Imran Bukhari, 2006, "Development of Mix Design for High Strength Concrete", 31st Conference on our world in concrete \&structures.

[3] Abdullahi, M., Al-Mattarneh, H.M.A., and Mohammed, B.S., 2010, "A Script File for Mix Design of Structural Lightweight Concrete, "Journal of Applied Sciences Research. 6(8), pp. 1132-1141.

[4] Abdullahi, M., Al-Mattarneh, H.M.A., and Mohammed, B.S., 2009, "A Mat lab Program for Diagnosis and Adjustment of Mix Proportions of Structural Lightweight Concrete,"European Journal of Scientific Research., 31(1), pp. 106-123.

[5] Krishnaswami, B.N., 2009, "Concrete mix design, "Technical meeting, Civil engineers \& architects association,

[6] Okoloekwe, R.C., andOkafor, F.O., 2007, "A new approach to concrete mix design using Computer techniques," Nigerian journal of technology. , 26(1), pp. 106-123.

[7] ACI Committee 211.4R-93 Guide for Selecting Proportions for High-Strength Concrete with Portland cement and Fly Ash.

[8] Abdullahi, M.,Al-Mattarneh, H.M.A., and Mohammed, B.S.,2009, "Equations forMix Design of Structural lightweight Concrete," European Journal Of ScientificResearch.,31(1)pp:132-141.

[9] Gan Ganju, T.N., 1996. Spread sheeting mix designs.ACI: Concrete international, 18(12): 35-38.

Fig 1: Flow chart representation of high strength concrete(Both Volume and weight basis)

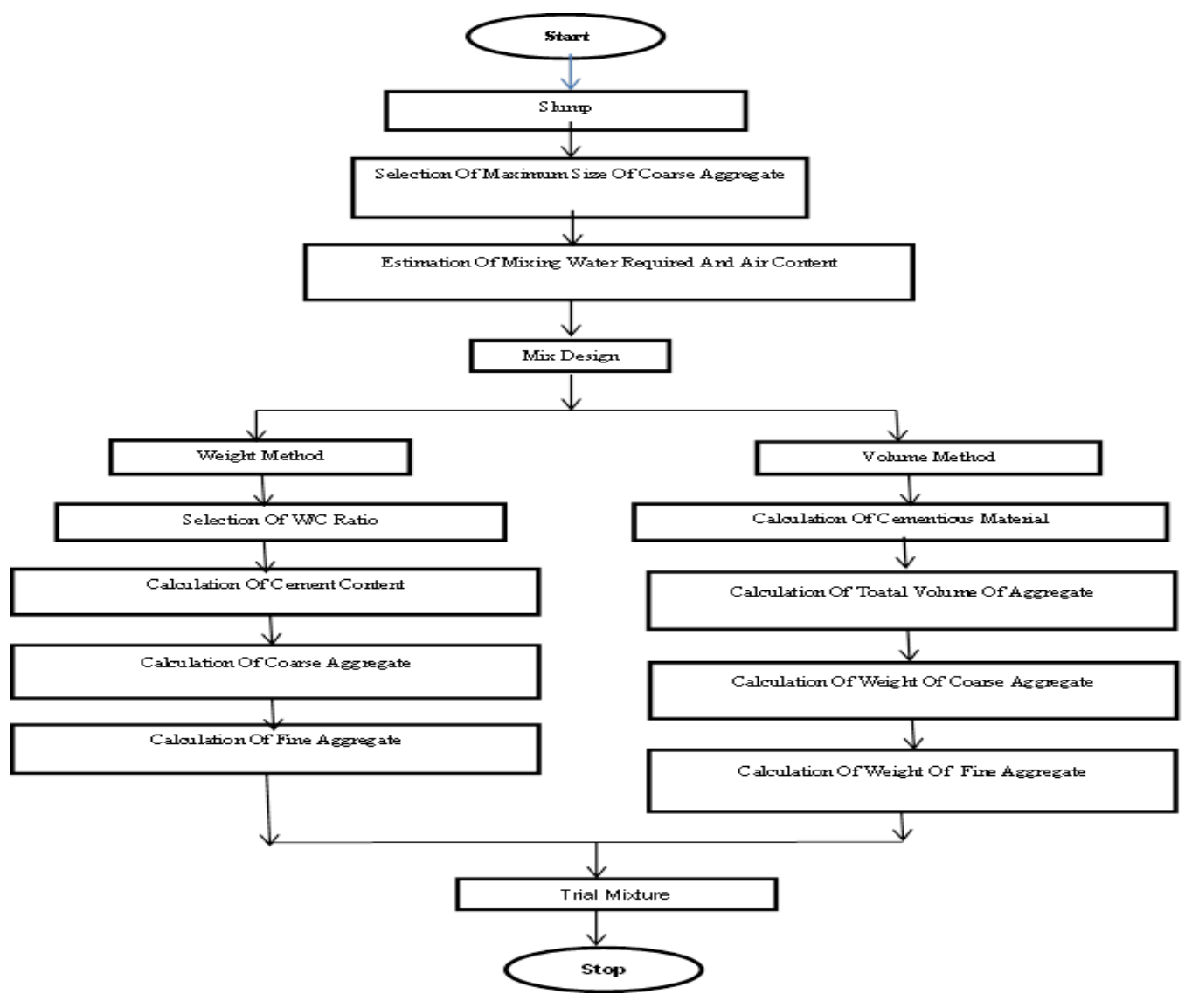




\section{APPENDIX A:}

\section{Mat lab Session for the Mix Design Problems}

\section{Case 1: Volume Method}

clc;

clear all;

$\%$ cs=input('compressive strength =');

$\%$ slump=input('slump =');

$\%$ sgcem=input('specific gravity of cement =');

$\%$ sgca=input('specific gravity of coarse aggregate $=$ ');

$\%$ sgfa=input('specific gravity of fine aggregate $=$ ');

$\%$ sca=input('size of coarse aggregate $=$ ');

$\%$ days=input('no. of days $(28$ or 56$)=$ ');

$\%$ hrwra = input('with hrwra -1 , without hrwra -0 ; enter 1 or $\left.0^{\prime}\right)$

cs $=8824$

slump $=2$

sgcem $=3.15$;

sgca $=2.76$

$\operatorname{sgfa}=2.59$

$\mathrm{sca}=0.5$

ae $=2$;

days $=28$;

hrwra $=1$;

$\%$ if $(\operatorname{cs}<=9000)$

$\% \quad$ sca $=\operatorname{randi}([0.751], 1,1)$

$\%$ elseif $(\mathrm{cs}>9000)$

$\% \quad \mathrm{sca}=\operatorname{rand}([.3750 .5], 1,1)$

$\%$ end

lock $=0$

$\mathrm{fcr}=1.10 *(\mathrm{cs})+700$

table1 = xlsread('fractionalvolume.xls')

$[\mathrm{m}, \mathrm{n}]=\operatorname{size}($ table 1$)$

for $\mathrm{i}=1: \mathrm{n}$

$$
\begin{aligned}
& \text { if }(\text { lock }==0) \\
& \operatorname{if}(\operatorname{table} 1(1, \mathrm{i})>\text { sca }) \\
& \text { lock }=1 ; \\
& \text { temp1 }=\operatorname{table} 1(1, \mathrm{i}) ; \\
& \text { temp2 }=\operatorname{table} 1(1, \mathrm{i}-1) ; \\
& \text { temp3 }=\operatorname{table} 1(2, \mathrm{i}-1) ;
\end{aligned}
$$

$$
\text { temp4 = table1 }(2, \mathbf{i}) \text {; }
$$

$\mathrm{fv}=($ temp $4 *(\mathrm{sca}-$ temp 2$)+$ temp $3 *($ temp $1-$ sca))/(temp1 - temp2); \% fractional volume of CA elseif $(\operatorname{table} 1(1, \mathrm{i})==\mathrm{sca})$

$$
\text { lock }=1 \text {; }
$$$$
\mathrm{fv}=\operatorname{table} 1(2, \mathrm{i}) \text {; }
$$

$\%$ fractional volume of $\mathrm{CA}$

$$
\begin{aligned}
& \text { end } \\
& \text { end }
\end{aligned}
$$$$
\text { end }
$$$$
\text { mca }=\mathrm{fv}^{*} 101 * 27 ; \quad \% \text { mass of CA }
$$

lock $=0$;

table2 = xlsread('amtofwater.xls');

$[\mathrm{m}, \mathrm{n}]=\operatorname{size}($ table 2$)$;

for $\mathrm{i}=2: \mathrm{m}$

if(table2(i,1)>=slump);

$$
\text { for } \mathrm{j}=2: \mathrm{n}
$$

if $($ lock $==0)$

$$
\begin{aligned}
& \text { if }(\operatorname{table} 2(1, \mathrm{j})>\mathrm{sca}) \\
& \text { lock }=1 \text {; } \\
& \text { temp1 = table } 2(1, \mathrm{j}) \text {; } \\
& \text { temp2 = table2 }(1, \mathrm{j}-1) \text {; } \\
& \text { temp3 = table2(i,j-1); } \\
& \text { temp4 = table2 }(\mathrm{i}, \mathrm{j}) \text {; } \\
& \mathrm{amtw}=(\text { temp } 4 *(\mathrm{sca}-\text { temp } 2)+
\end{aligned}
$$

temp3*(temp 1 - sca))/(temp1 - temp2); \% mixing water required

$$
\begin{aligned}
& \text { elseif }(\operatorname{table} 2(1, \mathrm{j})==\text { sca }) \\
& \text { lock }=1 ; \\
& \operatorname{amtw}=\operatorname{table} 2(i, j) ;
\end{aligned}
$$

$\%$ mixing water required

$$
\text { end }
$$

$$
\text { end }
$$

end

end

end

voidfa $=(1-(105 /(2.59 * 62.4))) * 100 ; \quad \%$ void content of fine aggregate

$\mathrm{mw}=($ voidfa -35$) * 8 ; \quad \%$ mixing water adjustment 
sfif $=((15 / 100) * a m t c m)$

$\%$ mix proportions using silica fume and cement

mcmfive $=($ amtcm-sfive $) ; \quad \%$ mass of cementious material for 5 percentage of silica fume

memten $=($ amtcm-sten $) ; \quad \%$ mass of cementious material for 10percentage of silica fume

mcmfif $=($ amtcm-sfif $) ; \quad \%$ mass of cementious material for 15 percentage of silica fume

\%TO FIND THE AMOUNT OF COARSE AGGREGATE CEMENT

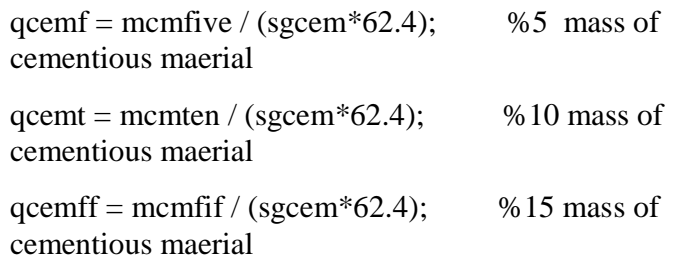
aggregate for mix two fmfamth $=(27-$ stotal $) ; \quad$ \%fmfa final mass of fine aggregate for mix three

\section{\%input}

$\%$ sgfa $=2.59 \quad \%$ rdfa relative density of fine aggregate

afamixon $=($ fmfamon $* 62.4 *$ sgfa $) ; \quad \%$ acamixon amount of fine aggregate for mix one

afamixtw $=($ fmfamtw $* 62.4 *$ sgfa $) ; \quad \%$ acamixtw amount of fine aggregate for mix two

afamixth $=($ fmfamth $* 62.4 *$ sgfa $) ; \quad \%$ acamixthamount of fine aggregate for mix three

fprintf('cement $=\%$ f kg ln',amtcm*0.454 );

fprintf('In mass of fine aggregate $=\% \mathrm{f} \mathrm{kg} \backslash \mathrm{n}$ ', $\left.\mathrm{mfa}^{*} 0.454\right)$;

fprintf('In mass of coarse aggregate $=\% \mathrm{f} \mathrm{kg}$ ln',mca*0.454);

fprintf('ไn water $=\%$ f kg \n',amtw*0.454 );

fprintf('In amount of fine aggregate for mix one $=\% \mathrm{f} \mathrm{kg}$ In',afamixon*0.454);

fprintf('In amount of fine aggregate for mix two $=\% \mathrm{f} \mathrm{kg}$ In',afamixtw*0.454);

fprintf('In amount of fine aggregate for mix three $=\% \mathrm{f} \mathrm{kg}$ In',afamixth*0.454);

fprintf('\n silica fume for mix one $=\%$ f kg $\backslash n$ ',sfive $* 0.454$ );

fprintf('ไn silica fume for mix two $=\% \mathrm{f} \mathrm{kg} \ln$ ',sten*0.454 );

fprintf('\n silica fume for mix three $=\% \mathrm{f} \mathrm{kg} \backslash \mathrm{n}$ ',sfif*0.454 )

fprintf('In mass of cementious maerial for mix one $=\% \mathrm{f}$ $\mathrm{kg} \backslash \mathrm{n}$ ',momfive*0.454 );

fprintf('In mass of cementious maerial for mix two $=\% \mathrm{f}$ $\mathrm{kg} \backslash \mathrm{n}$ ',momten*0.454);

fprintf('In mass of cementious maerial for mix three $=\% \mathrm{f}$ $\mathrm{kg} \backslash \mathrm{n}$ ',momfif*0.454);

\section{APPENDIX B: Matlab Session for the Mix Design Problems}

\section{Case 2: Weight Method}

clear all; 
clc;

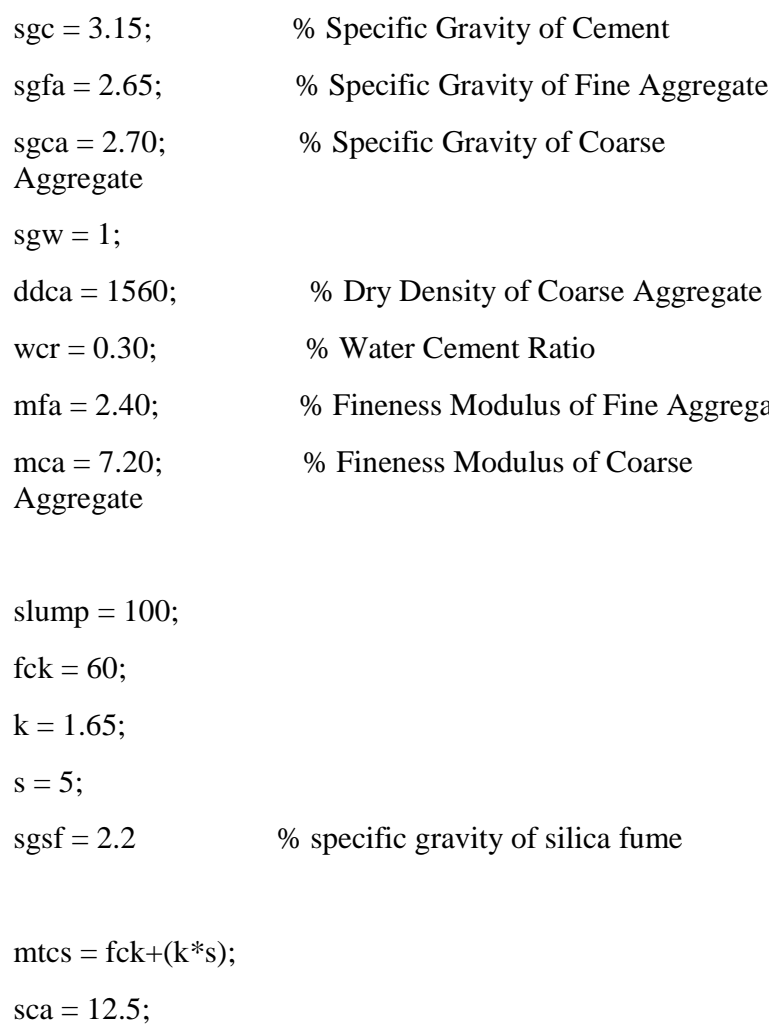

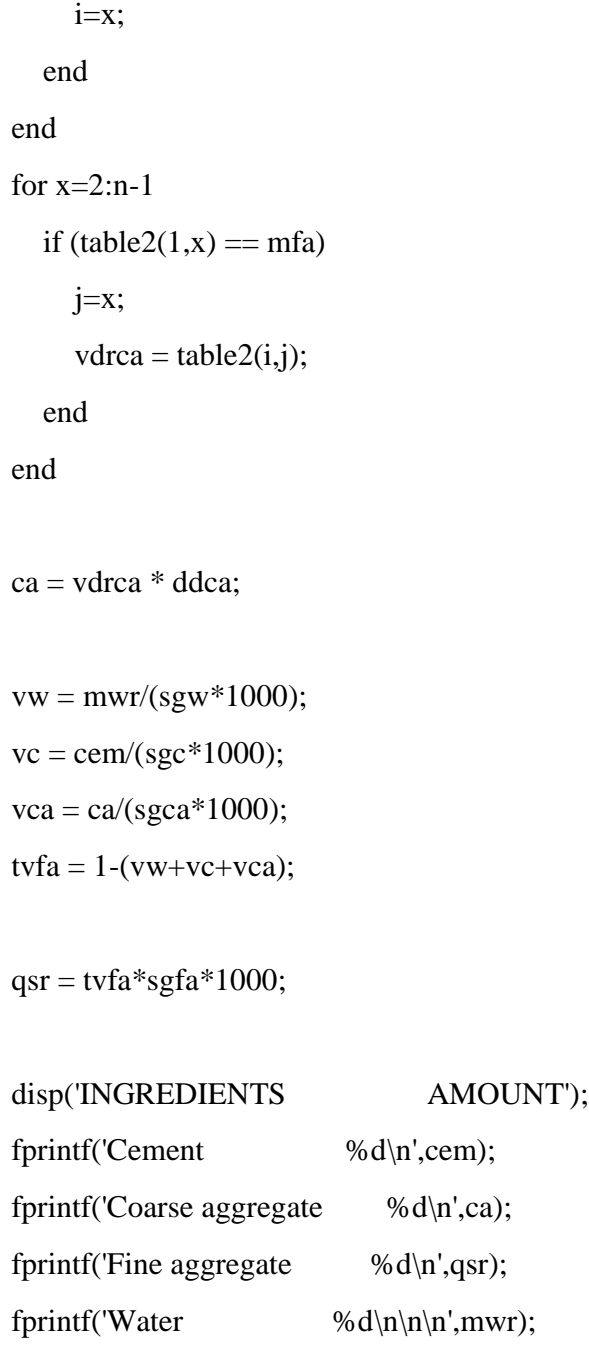

$\%$ trial mix one with $5 \%$ of silica fume 
$\mathrm{vw}=\mathrm{mwr} /\left(\mathrm{sgw}^{*} 1000\right)$;

vctrone $=$ cemfive $/(\operatorname{sgc} * 1000) ; \quad \%$ volume of cement for trial one

vsftrone $=\operatorname{sffive} /(\operatorname{sgsf} * 1000)$

$\%$ volume of silica fume

for trial one

$\mathrm{vca}=\mathrm{ca} /(\operatorname{sgca} * 1000)$;

tvfatrone 1 = 1-(vw+vca+vctrone+vsftrone $)$; \%total volume of fine aggregate for trial one

qsr1 = tvfatrone $1 *^{\text {sgfa }} * 1000$;

$\%$ trial mix one with $10 \%$ of silica fume

$\mathrm{vw}=\mathrm{mwr} /\left(\operatorname{sgw}^{*} 1000\right)$

vctrtwo $=\operatorname{cemten} /(\operatorname{sgc} * 1000) ; \quad \%$ volume of cement for trial two

vsftrtwo $=\operatorname{sften} /(\operatorname{sgsf} * 1000) ; \quad \%$ volume of silica fume for trial two

$\mathrm{vca}=\mathrm{ca} /(\operatorname{sgca} * 1000)$;

tvfatrone 2 = 1-(vw+vca+vctrtwo+vsftrtwo $)$; \%total volume of fine aggregate for trial two

qsr2 $=$ tvfatrone $2 *$ sgfa $* 1000 ;$ \%trial mix one with $15 \%$ of silica fume

$\mathrm{vw}=\mathrm{mwr} /\left(\mathrm{sgw}^{*} 1000\right)$;

vctrthree $=$ cemfif $/(\operatorname{sgc} * 1000) ; \quad \%$ volume of cement for trial three

vsftrthree $=$ sffif $/(\operatorname{sgsf} * 1000) ; \quad \%$ volume of silica fume for trial three

$\mathrm{vca}=\mathrm{ca} /(\operatorname{sgca} * 1000) ;$

tvfatrone3 = 1-(vw+vca+vctrthree+vsftrthree $)$; \%total volume of fine aggregate for trial three

qsr3 = tvfatrone $3 *$ sgfa* 1000 ;

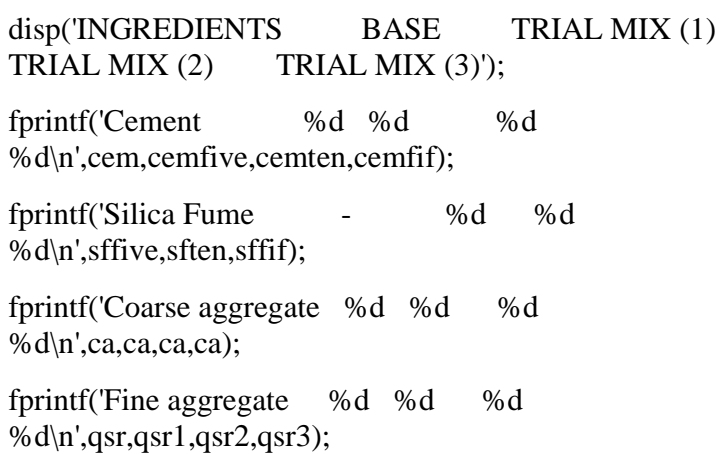

